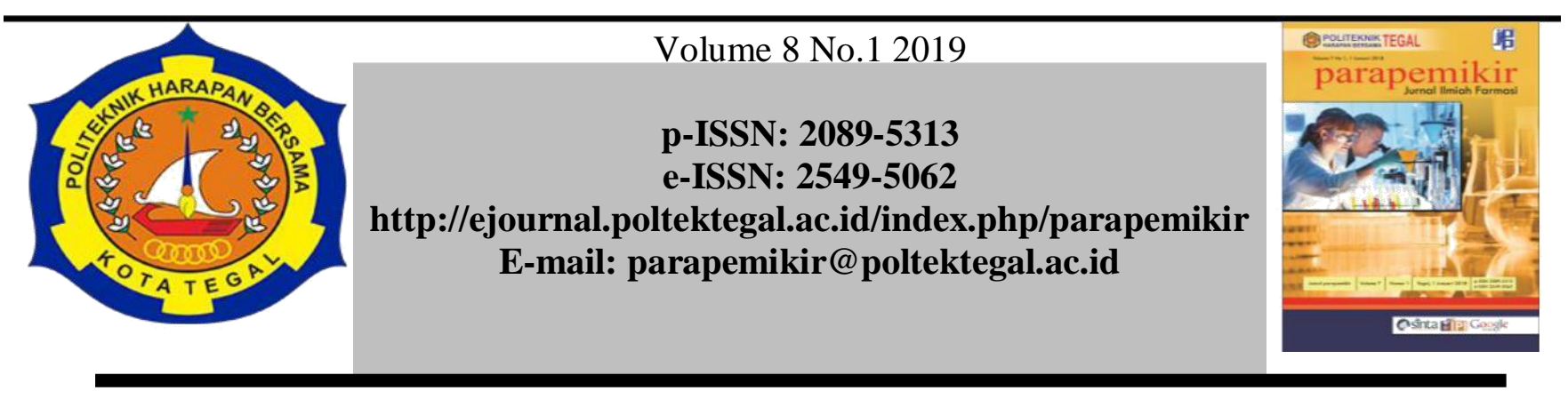

\title{
PENGARUH PERBEDAAN BAHAN PENGIKAT KARBOMER, METHYL CELLULOSA DAN KOMBINASINYA TERHADAP SIFAT FISIK SEDIAAN EYELINER DARI ARANG BATOK KELAPA
}

\author{
Rizki Febriyanti ${ }^{1}$, Akhmad Aniq Barlian ${ }^{2}$ \\ 12 Program Studi DIII Farmasi Politeknik Harapan Bersama, \\ Jalan Mataram No 9 Kota Tegal 52142, Indonesia \\ Email : rizki.febriyanti83@gmail.com
}

\begin{tabular}{|c|c|}
\hline Article Info & Abstrak \\
\hline Article history: & \multirow{2}{*}{$\begin{array}{l}\text { Eyeliner merupakan kosmetik yang sering digunakan oleh wanita, Dimana eyeliner } \\
\text { merupakan contoh kosmetik riasan dekoratif yang berfungsi mempercantik dan } \\
\text { menegaskan bentuk mata. Untuk mengembangkan produk eyeliner, bahan penting yang }\end{array}$} \\
\hline $\begin{array}{l}\text { Received Desmber } \\
2018\end{array}$ & \\
\hline Received in & \multirow{8}{*}{$\begin{array}{l}\text { mengetahui karbon dari arang batok kelapa dapat dimanfaatkan menjadi produk } \\
\text { kosmetik eyeliner dengan bahan pengikat yang berbeda-beda dan untuk mengetahui } \\
\text { formula dengan bahan pengikat yang memberikan sifat fisik paling baik pada sediaan } \\
\text { eyeliner dari arang batok kelapa. Penelitian ini menggunakan metode eksperimen } \\
\text { laboratorium yaitu dengan mencampurkan bahan pengikat karbomer, MC maupun } \\
\text { kombinasi keduanya, etanol } 96 \% \text {, metal paraben, aquadest, dan menambahkan karbon } \\
\text { aktif di dalamnya. Dilakukan pengujian sifat sediaan yaitu uji homogenitas, uji pH, uji } \\
\text { oles, uji iritasi terhadap kulit sukarelawa serta uji kesukaan terhadap sediaan eyeliner. } \\
\text { Hasil penelitian menunjukan bahwa arang batok kelapa dapat digunakan pada sediaan } \\
\text { eyelinerdan formula yang memiliki uji sifat fisik paling disukai adalah formula III } \\
\text { dengan dengan bahan pengikat kombinasi karbomer dan MC dengan konsentrasi } \\
\text { masing-masing } 1 \% \text {. }\end{array}$} \\
\hline revised form & \\
\hline Desember 2018 & \\
\hline Accepted Januari & \\
\hline 2019 & \\
\hline Available online & \\
\hline January 2019 & \\
\hline $\begin{array}{l}\text { Kata kunci: } \\
\text { eyeliner, karbomer, } \\
\text { MC, kombinasi, uji } \\
\text { sifat fisik. }\end{array}$ & \\
\hline \multirow{3}{*}{$\begin{array}{l}\text { Keywords: eyeliner, } \\
\text { carbomer, MC, } \\
\text { combination, physical } \\
\text { properties test }\end{array}$} & abstract \\
\hline & $\begin{array}{l}\text { Eyeliner is a cosmetic that is often used by women, where eyeliner is an example of } \\
\text { decorative makeup cosmetics that function to beautify and confirm the shape of the } \\
\text { eyes. To develop eyeliner products, the important ingredients used are carbon and } \\
\text { binder. The purpose of this study is to find out that carbon from coconut shell charcoal } \\
\text { can be used as cosmetic eyeliner products with different binding materials and to find } \\
\text { out formulas with binders that provide physical properties. best on eyeliner } \\
\text { preparations from coconut shell charcoal. This study uses a laboratory experimental } \\
\text { method that is by mixing carbomer binder, MC and a combination of both, } 96 \% \\
\text { ethanol, paraben metal, aquadest, and adding activated carbon in it. The properties of } \\
\text { the dosage were tested, namely homogeneity test, pH test, topical test, irritation test on } \\
\text { voluntary skin, and test of preference for eyeliner preparations. The results showed that } \\
\text { coconut shell charcoal can be used in eyeliner preparations and the formula which has } \\
\text { the most preferred physical properties test is formula III with a carbomer and MC } \\
\text { combination binder with a concentration of } 1 \% \text { each. }\end{array}$ \\
\hline & \\
\hline
\end{tabular}


Rizki Febriyanti , Akhmad Aniq Barlian Vol 8 (1) 2019 pp 36-40

\section{Alamat korespondensi:}

Prodi DIII Farmasi Politeknik Harapan Bersama Tegal

Gedung A Lt.3. Kampus 1

J1. Mataram No. 09 Kota Tegal, Kodepos 52122

Telp. (0283) 352000

p-ISSN: 2089-5313

E-mail: parapemikir_poltek@yahoo.com

e-ISSN: 2549-5062 


\section{Pendahuluan}

Kosmetik menjadi salah satu produk perawatan yang digunakan oleh sebagian besar wanita ${ }^{1}$, salah satunya adalah eyeliner kosmetik yang paling sering digunakan oleh sebagian besar wanita untuk mempercantik dan menegaskan bentuk mata digunakan disekeliling kontur mata

Karbon yang berasal dari tempurung kelapa yang digunakan untuk kesehatan dan kecantikan kemudian diaktivasi yang bertujuan memperbesar luas permukaan arang dengan cara membuka pori-pori yang tertutup sehingga akan memperbesar kapasitas adsorbsi terhadap zat warna ${ }^{2}$. Pada pembuatan sediaan eyeliner dibutuhkan formula untuk menghasilkan sediaan yang terstandar. Salah satu bahan terpenting dalam formulanya adalah adanya bahan pengikat. Bahan pengikat yang digunakan dalam penelitian ini adalah Karbomer, Methyl Cellulosa atau biasa disingkat dengan istilah MC dan kombinasi dari kedua bahan pengikat tersebut. Karbomer merupakan polimer dengan berat molekkul yang tinggi, sering digunakan dalam formulasi sediaan farmasi cair atau semi padat untuk mengubah reologi/ sifat alir dari sediaan tersebut. Formulasi tersebut termasuk krim, gel, lotion dan salep untuk sediaan mata $\mathrm{dll}^{3}$. Sedangkan Methyl Cellulosa merupakan golongan selulosa yang bersifat higroskopis, praktis tidak berbau dan tidak berasa ${ }^{3}$ sehingga sangat cocok apabila digunakan untuk formulasi pada sediaan gel. Penelitian disini bertujuan untuk mengetahui karbon dari arang batok kelapa dapat dimanfaatkan menjadi produk kosmetik eyeliner dengan bahan pengikat yang berbeda-beda dan untuk mengetahui formula dengan bahan pengikat yang memberikan sifat fisik paling baik pada sediaan eyeliner dari arang batok kelapa.

\section{Metodologi Penelitian}

Alat : neraca analitik, stick $\mathrm{pH}$, cawan porselen, mesh 120, batang pengaduk gelas ukur, gelas beker, dan object glass.

Bahan : karbon aktif tempurung kelapa, alkohol $96 \%$, aquades, carbomer, metil p-hidrobenzoat.

Prosedur Penelitian

1. Pembuatan karbon aktif dari tempurung kelapa Batok kelapa dibuat menjadi arang dengan cara pembakaran, yang selanjutnya dilakukan proses aktivasi dengan menggunakan furnance.

2. Pembuatan sediaan eyeliner. Pembuatan eyeliner diawali dengan mengayak serbuk kabon aktif menggunakan mesh 120. Metil p-hidrobenzoat dilarutkan dalam etanol, carbomer dibasahi dengan etanol, kemudian campuran tersebut ditambahkan ke dalam aquades. Kemudian karbon aktif didispersikan ke dalam campuran tersebut dan dihomogenkan.

Penentuan Mutu Fisik Sediaan Eyeliner

a. Uji Organoleptik
Uji organoleptik dimaksud untuk melihat tampilan fisik fisik sediaan yang meliputi bentuk, warna dan bau.

b. Uji Homogenitas

Uji homogenitas menggunakan object glass dengan cara: sejumlah tertentu sediaan dioleskan pada object glass kemudian mengamati apakah sediaan homogen atau terdapat butiran kasar.

c. Uji pH

Sampel dibuat dalam konsentrasi $1 \%$ yaitu ditimbang 1 gram sediaan dan diencerkan dalam gelas beker dengan akuades hingga 100 $\mathrm{ml}$. Keras $\mathrm{pH}$ dicelupkan kedalam larutan tersebut, kemudian dicocokkan pada indikator $\mathrm{pH}$. Nilai $\mathrm{pH}$ penting untuk mengetahui tingkat keasaman dari sediaan agar tidak mengiritasi kulit. Sehingga $\mathrm{pH}$ sediaan kosmetik harus sesuai dengan $\mathrm{pH}$ kulit, yaitu antara 4,5-7, $0^{4}$.

d. Uji Iritasi

Percobaan ini dilakukan pada 6 orang panelis dengan cara mengoleskan sediaan pada kulit bagian dalam lengan bawah selama 2 hari berturut-turut ${ }^{4}$. Kemudian diamati terjadinya eritema dan edema ${ }^{5}$.

e. Uji Oles

Uji oles dengan cara mengoleskan eyeliner pada bagian punggung tangan. Pelepasan eyeliner yang tidak baik ditunjukan dengan sedikitnya eyeliner yang menempel pada punggung tangan dan terputus-putus, pelepasan eyeliner yang baik ditunjukan dengan eyeliner yang menempel pada punggung tangan dan tidak terputus-putus ${ }^{6}$.

\section{HASIL DAN PEMBAHASAN}

a. Uji Organoleptik

Uji organoleptik mengamati bentuk, warna, dan aroma.

Tabel 1. Uji Organoleptik

\begin{tabular}{|c|c|c|c|}
\hline Formula & Bentuk & Warna & Aroma \\
\hline I & $\begin{array}{l}\text { Paling } \\
\text { Kental }\end{array}$ & Hitam & Tidak berbau \\
\hline II & $\begin{array}{l}\text { Agak } \\
\text { kental }\end{array}$ & Hitam & Tidak berbau \\
\hline III & Kental & Hitam & Tidak berbau \\
\hline
\end{tabular}

Keterangan :

Formula I : Eyeliner dengan bahan pengikat karbomer

Formula II : Eyeliner dengan bahan pengikat MC

Formula III : Eyeliner dengan bahan pengikat kombinasi karbomer dan MC

Hasil pengamatan organoleptik menunjukan bahwa tiap formula sediaan eyeliner yang dibuat memiliki warna dan aroma yang sama yaitu berwarna hitam dan tidak berbau, tetapi dari segi bentuk memiliki masing-masing formula memiliki perbedaan. Pada formula I menghasilkan bentuk 
yang lebih kental dimana sesuai dengan karakteristik karbomer sebagai gelling agent akan dihasilkan sediaan yang kental apalagi dengan konsentrasi maksimal dari karbomer yang digunakan. Sedangkan pada formula II menghasilkan bentuk yang agak kental dibanding formula III yang kental. Dimana formula II menggunakan MC sebagai bahan pengikatnya dan MC merupakan golongan selulosa yang secara karakteristik mudah larut dalam air pada sediaan liquid maupun semi solid. Sehingga sediaan yang dibuatpun dalam konsentrasi yang maksimal pun masih aman

\section{b. Uji Homogenitas}

Pengujian homogenitas untuk mengetahui homogen tidaknya eyeliner yang dihasilkan. Homogenitas mencerminkan tidak terbentuknya partikel-partikel yang memisah.

Tabel 2. Uji Homogenitas

\begin{tabular}{ccc}
\hline Formula & Homogenitas & Literatur \\
\hline I & Tidak Homogen Tidak terlihat adanya \\
II & Tidak Homogen & $\begin{array}{c}\text { gelembung udara, } \\
\text { gumpalan dan } \\
\text { partikel yang } \\
\text { terpisah }\end{array}$ \\
III & Tidak Homogen & \begin{tabular}{c} 
Tisal \\
\hline
\end{tabular}
\end{tabular}

Keterangan :

Formula I : Eyeliner dengan bahan pengikat karbomer

Formula II : Eyeliner dengan bahan pengikat MC

Formula III : Eyeliner dengan bahan pengikat kombinasi karbomer dan MC

Hasil pengamatan bahwa sediaan eyeliner formula I, II dan III yang dihasilkan tidak homogen. Hal ini dikarenakan serbuk arang batok kelapa yang kurang larut dalam sediaan eyeliner, disebabkan karena serbuk arang batok kelapa yang kurang halus atau sifatnya yang tidak larut dalam air.

\section{c. $\quad \mathrm{Uji} \mathrm{pH}$}

Pengujian $\mathrm{pH}$ eyeliner bertujuan untuk mengetahui nilai keasaman pada eyeliner dan mengetahui sesuai tidaknya $\mathrm{pH}$ eyeliner dengan standar yang ditentukan. Sehingga sediaan kosmetik harus sesuai dengan $\mathrm{pH}$ kulit, yaitu antara 4,5-7, $0^{4}$.

Tabel 3. Uji pH

\begin{tabular}{ccc}
\hline Formula & Uji pH & Syarat \\
\hline I & 5 & \\
II & 5 & $4,5-7,0^{[4]}$ \\
III & 5 & \\
\hline
\end{tabular}

Hasil pengamatan $\mathrm{pH}$ menunujukan bahwa sediaan eyeliner baik pada formula I, II dan III memiliki pH

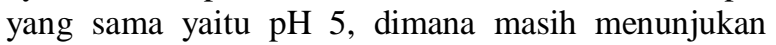
kisaran $\mathrm{pH}$ yang sesuai dengan $\mathrm{pH}$ kulit yaitu 4,5-7,0 sehingga tidak beresiko menimbulkan reaksi negatif pada kulit. Jadi dapat disimpulkan bahwa perbedaan bahan pengikat tidak mempengaruhi terhadap nilai $\mathrm{pH}$ sediaan yang dibuat.

\section{d. Uji Iritasi}

Pengujian iritasi bertujuan untuk mengetahui terjadinya iritasi pada saat dioleskan pada kulit lengan bawah, dimana reaksi yang diamati terjadinya eritema dan edema.

Tabel 4. Uji Iritasi

\begin{tabular}{ccccc}
\hline \multirow{2}{*}{ Pernyataan } & \multirow{2}{*}{ Eyeliner } & \multicolumn{3}{c}{ Relawan } \\
\cline { 3 - 5 } Eritema & FI & I & II & III \\
\hline \multirow{2}{*}{ Edema } & FII & - & - & - \\
& FIII & - & - & - \\
\hline \multirow{2}{*}{ FI } & - & - & - \\
& FII & - & - & - \\
& FIII & - & - & - \\
\hline
\end{tabular}

Keterangan :

$+\quad$ : Terjadi reaksi

- $\quad$ : Tidak terjadi reaksi

Hasil pengamatan uji iritasi kulit untuk mengetahui terjadinya efek samping pada kulit, dengan memakai eyeliner pada kulit bagian dalam lengan bawah selama 2 hari berturut-turut, ternyata tidak terlihat adanya efek samping berupa eritema dan edema pada kulit yang ditimbulkan oleh sediaan.

\section{e. Uji Oles}

Uji oles dilakukan secara visual dengan cara mengoleskan sediaan eyeliner pada kulit punggung tangan. Pelepasan zat warna yang tidak baik ditunjukan dengan sedikitnya warna yang menempel pada kulit punggung tangan, pelepasan zat warna yang baik ditunjukan dengan banyaknya warna yang dilepaskan dan menempel dengan baik pada punggung tangan.

Pemeriksaan dilakukan terhadap masing-masing sediaan dari tiap formula yang dibuat dan dioleskan pada kulit punggung tangan. Semakin sedikit pengolesan maka semakin baik sediaan dan sebaliknya semakin banyak pengolesan maka kurang baik sediaan eyeliner tersebut. Diperoleh dari masing-masing formula eyeliner formula III dengan bahan pengikat kombinasi karbomer dan MC mengasilkan pelepasan zat warna yang baik dengan warna hitam yang menempel dengan baik pada punggung tangan, sedangkan eyeliner formula I dengan bahan pengikat karbomer dan formula II dengan bahan pengikat MC menghasilkan pelepasan zat warna yang baik dengan warna hitam tetapi tidak menempel dengan baik pada punggung tangan.

\section{KESIMPULAN}

Hasil penelitian dapat disimpulkan bahwa Karbon dari arang batok kelapa dapat dimanfaatkan menjadi produk kosmetik eyeliner dengan bahan pengikat yang berbeda-beda dan Formula dengan yang memberikan sifat fisik paling baik pada sediaan Eyeliner dari Arang Batok Kelapa adalah pada formula III dengan menggunakan bahan pengikat kombinasi Karbomer dan Methyl cellulosa. 


\section{REFERENSI}

[1] Safitri, Meta dkk. 2016. Pengembangan formulasi dan evaluasi fisik sediaan krim ekstrak etanol $70 \%$ daun labu siam(Sechium edule (Jacq.)Swatz).Vol3. Sekolah Menengah Kejuruan, Direktorat Jenderal Manajemen Pendidikan Dasar dan Menengah, Departemen Pendidikan Nasional.

[2] Arsad, E. danHamdi, S. 2010.Jurnal Riser IndustriHasilHutan.2. (2) : 44-46

[3] Rowe, Raymond C., dkk 2009, Handbook of pharmaceutical Excipient, VIEdition. London ; Pharmaceutical Press.

Rowe, Raymond C., dkk 2009, Handbook of pharmaceutical Excipient, Sixth Edition. London ; Pharmaceutical Press.
Rowe, Raymond C., dkk 2009a, Handbook of pharmaceutical Excipient, Sixth Edition. London; Pharmaceutical Press.

Rowe, Raymond C., dkk 2009b, Handbook of pharmaceutical Excipient, Sixth Edition. London ; Pharmaceutical Press.

[4] Wasitaatmadja, S.M. (1997). Penuntun Ilmu Kosmetik Medik. Jakarta: UI Press. 33-37

[5] Barel, A.O., Marc. P., Howard, I.M. (2001). Hanbook of Cosmetic Science and Technology. New York: Marcel Dekker, Inc. Halaman 110, 664-665.

[6] Masumah, Lif Anis. 2017. Formulasi dan Uji Sifat Fisik Sediaan Blush On Dari Ekstrak Kayu Secang (Caesalpinia sappan L.). 